\title{
Fluctuating disinhibition: implications for the understanding and treatment of alcohol and other substance use disorders
}

\author{
Andrew Jones ${ }^{1}$, Paul Christiansen ${ }^{1}$, Chantal Nederkoorn ${ }^{2}$, Katrijn Houben ${ }^{2}$ and Matt Field ${ }^{1 *}$ \\ 1 Department of Psychological Sciences, University of Liverpool, Liverpool, UK \\ ${ }^{2}$ Clinical Psychological Science, Maastricht University, Maastricht, Netherlands
}

Edited by:

Antonio Verdejo-García, Universidad de Granada, Spain

\section{Reviewed by:}

Otto Lesch, Medical University of

Vienna, Austria

Luigi Janiri, Università Cattolica del S. Cuore, Italy

\section{*Correspondence:}

Matt Field, Department of

Psychological Sciences, University of Liverpool, Eleanor Rathbone Building, Bedford Street South, Liverpool

L69 7ZA, UK

e-mail:mfield@liv.ac.uk
Disinhibition is present in various maladaptive behaviors, including substance use disorders. Most previous research has assumed that disinhibition is a psychological construct that is relatively stable within individuals. However, recent evidence suggests that the ability to inhibit behavior fluctuates in response to environmental and psychological triggers. In this review we discuss some of the factors that cause (dis)inhibition to fluctuate, we examine whether these fluctuations contribute to subjective craving and substance consumption, and we ask if they might increase the risk of relapse in those who are attempting to abstain. The research that we discuss has furthered our understanding of the causal relationships between disinhibition and substance use disorders, and it also highlights opportunities to develop novel treatment interventions. We conclude that substance misusers and their therapists should be made aware of the triggers that can cause disinhibition to fluctuate, and we highlight the need for more research to investigate the effectiveness of inhibitory control training in clinical settings.

\section{INTRODUCTION}

The constructs of impulsivity and (poor) executive functioning are central to substance use disorders and other addictive behaviors (1). These constructs are multifaceted and consist of subcomponents which include sensitivity to reward, preference for immediate gratification, risk taking, and disinhibition (2). Disinhibition is defined as the inability to suppress, delay, or change a response that is no longer required or is inappropriate. This inability to control behavior can be measured in the laboratory using computer tasks, such as the Stop Signal (3) and Go/No-Go (4) tasks, both of which require participants to inhibit a dominant motor response. The (in)ability to control oculomotor reflexes is another index of disinhibition: for example, the anti-saccade and delayed ocular return tasks require individuals to suppress or delay reflexive saccades to visual stimuli $(5,6)$.

Impaired ability to control behavior is specified in at least one of the DSM 5 criteria for substance use disorders ["persistent desire or unsuccessful effort to cut down or control (substance) use"; American Psychiatric Association, 2013]. Consistent with this, there is overwhelming evidence for increased disinhibition (or poor inhibitory control) in substance abusers, alongside elevations in other aspects of impulsivity [for a comprehensive review see (7)]. For example, alcohol-dependent patients perform worse on the Stop Signal task than healthy controls (8-10). Furthermore, different subtypes of alcoholism may show more pronounced disinhibition than others $(10,11)$. Elevated disinhibition is also seen in abusers of cocaine (12) and methamphetamine (13), and in cigarette smokers (14).
In individuals who drink alcohol but are not dependent, Colder and O'Connor (15) found that an index of disinhibition (commission errors on a Go/No-Go task) was associated with alcohol use. Other studies have also shown that elevated motor disinhibition is associated with problem drinking in community samples of non-dependent drinkers (16-18), although this relationship is not always seen $(19,20)$. Weafer et al. (6) demonstrated that oculomotor disinhibition predicted heavy drinking in individuals with Attention Deficit Hyperactivity Disorder (ADHD), but not in healthy controls. We direct readers to recent reviews of the relationship between substance use and disinhibition from Verdejo-Garcia et al. (7) and Dick (21).

There is some debate over whether disinhibition is a cause or a consequence of substance use. There are two possible explanations, which are not mutually exclusive: (i) chronic heavy substance use may increase disinhibition through neurotoxic effects in the prefrontal cortex, and (ii) children and adolescents who are particularly disinhibited are at increased risk of initiating substance use and developing substance use disorders. In support of the first explanation, it is well-established that chronic alcoholics present with structural brain damage, with prefrontal areas showing the greatest damage associated with heavy drinking (22, 23). These prefrontal regions are implicated in executive functions, including disinhibition, so structural and functional damage here should correspond to disinhibited behavior (24-26). Furthermore, animal research reveals that chronic alcohol administration and/or binge cycles causes structural and functional damage to the brain (27-29). 
On the other hand, individual differences in disinhibition may explain why some adolescents start to use alcohol and drugs at a young age and then develop substance use disorders, whereas others do not. A series of longitudinal studies have demonstrated that increased disinhibition during childhood is a risk-factor for substance abuse in later life (30-32). One study examined the developmental trajectory of behavioral control and demonstrated that children with lower levels and who exhibited slower development (of behavioral control) were more likely to report alcohol-related problems at later time points (33). Other studies have investigated "neurobehavioral disinhibition," a latent variable derived from questionnaire measures and observer reports of executive cognitive functioning and disruptive behavior and have found that disinhibition at age 12 predicts later substance use behaviors $(31,32)$. Using a cross lagged model, Fernie et al. (34) demonstrated that disinhibition predicted alcohol use 6 months later in British schoolchildren, although they found no evidence for alcohol-induced impairments in inhibitory control. Furthermore, in adults, disinhibition in heavy drinkers has been shown to predict severity of alcohol dependence at 4 years follow-up (35). Finally, children with ADHD demonstrate disinhibited behavior, and affected children are significantly more likely to develop alcohol dependence (36).

\section{DOES DISINHIBITION FLUCTUATE OVER TIME?}

Whilst these prospective studies suggest that elevated disinhibition is a risk-factor for heavy drinking, this does not necessarily imply that disinhibition is purely a trait variable, i.e., one that is stable over time with individuals. On the contrary, there is now solid evidence that disinhibition, like other states, can fluctuate within individuals. In a recent review of the literature, de Wit (2) noted that "... abrupt environmental, physiological, or emotional events may cause transient "state" changes in either self-control or inhibition that may result in re-initiation of drug use" (p.28). In the remainder of this review we will discuss the psychological mechanisms that underlie state fluctuations in disinhibition, and we investigate whether temporary increases in disinhibition are associated with increased subjective craving and self-administration of the substance. We note here that whilst we have attempted to organize this material into distinct categories, there is likely to be considerable overlap between categories and we highlight this at appropriate points in our manuscript.

\section{THE PHARMACOLOGICAL EFFECTS OF ALCOHOL: "PRIMING"}

Acute alcohol intoxication, or alcohol “priming," leads to increased desire for and self-administration of alcohol (37), effects which are dose-dependent (38). As well as increasing motivation to drink, alcohol priming also leads to changes in cognitive functions, including disinhibition. For example, moderate $(0.4 \mathrm{~g} / \mathrm{kg})$ to large $(0.8 \mathrm{~g} / \mathrm{kg})$ doses of alcohol impair inhibitory control on a variety of behavioral measures $(39,40)$. Furthermore, these deficits are evident at doses too low to disrupt general psychomotor performance, suggesting fairly selective effects of acute alcohol on disinhibition [see detailed reviews from Fillmore (41) and (42)]. More recent research demonstrates that the effects of alcohol intoxication on disinhibition may be particularly pronounced when participants are required to inhibit their responding to alcohol cues (43) [but see (44)], a point that we return to later.

Given that disinhibition is sensitive to acute alcohol consumption, it has been hypothesized that fluctuations in disinhibition may mediate the alcohol priming effect, i.e., the "loss of control" over drinking that occurs following alcohol ingestion (42). This prediction was based on findings reported by Weafer and Fillmore (45), who demonstrated that consumption of $0.65 \mathrm{~g} / \mathrm{kg}$ of alcohol led to increased commission errors on a Go/No-Go task. Importantly, those authors found that the magnitude of alcohol-induced disinhibition was positively correlated with ad libitum alcohol consumption in a subsequent testing session (when participants were sober), with alcohol-induced disinhibition accounting for $20 \%$ of the variance in alcohol consumption.

While informative, this study does not tell us if alcohol-induced increases in disinhibition are related to alcohol-induced increases in the motivation to drink alcohol, i.e., if alcohol-induced disinhibition might mediate the alcohol priming effect. In the first study to directly investigate this issue, we (46) found that alcohol administration led to increased ad-libitum alcohol consumption, but it did not affect disinhibition (performance on a Go/No-Go task), and disinhibition was unrelated to ad libitum alcohol consumption after alcohol administration. In summary, at present there is no convincing evidence to suggest that state fluctuations in disinhibition mediate the alcohol priming effect, although to date only one study has directly tested this hypothesis.

It is also important to point out that disinhibition can fluctuate in sober people, in response to non-pharmacological manipulations, and these manipulations may influence the motivation to drink alcohol and contribute to loss of control over drinking behavior. We review these environmental and psychological influences on disinhibition in the next sections of the paper.

\section{EGO DEPLETION}

The Limited Resource theory of self-control (47) posits that individuals have a finite reserve of self-control that they can employ to regulate their behavior. If demands on self-control are excessive and/or maintained over a long period of time then this resource will become depleted and subsequent attempts to regulate behavior will be unsuccessful; the state of having depleted self-control resources has been termed "Ego Depletion." The analogy of selfcontrol as a muscle is often used: in the same way that repeated exertion of a muscle over a short period of time will weaken that muscle and lead to fatigue, self-control capacity will be diminished after exerting self-control for a prolonged period $(47,48)$. In relation to substance use, individuals may need to engage self-control in order to overcome urges or cravings to use the substance when they encounter substance-related cues. For example, Muraven and Shmueli (49) found that when social drinkers were exposed to alcohol cues, they showed greater disinhibition than when exposed to neutral cues. A similar pattern of results was reported by Gauggel et al. (50) in detoxified alcohol-dependent patients [although a subsequent study failed to replicate this (51)]. One explanation for these findings is that alcohol abusers have to engage self-control resources in order to resist their urge to drink alcohol when exposed to alcohol cues, and this leads to a depletion 
of self-control resources, which manifests as increased disinhibition. However, it is important to point out that ego depletion is not the only explanation for increased disinhibition after cue exposure, a point that we address in the next section.

As predicted by limited resource theory, alcohol consumers are more likely to drink to excess if they have been exerting self-control. Muraven et al. (52) demonstrated that a self-control task (thought suppression) led to increased alcohol consumption compared to a comparison task that did not require self-control (performing mental arithmetic). Furthermore, this increase in alcohol consumption was evident despite participants being given a financial incentive to limit their alcohol consumption. Comparable findings were reported by Friese et al. (53). The influence of ego depletion was also examined in naturalistic settings by Muraven et al. (54), who used ecological momentary assessment to assess self-control demands and alcohol consumption. They found that on days when individuals reported higher self-control demands (expending more effort in regulating mood, controlling thoughts, or dealing with stress), they tended to drink more alcohol and were more likely to violate self-imposed limits on alcohol consumption [c.f. Limit Violation Theory: $(55,56)]$. Combined, these studies suggest that ego depletion can have a causal influence on drinking behavior, and temporarily increased disinhibition (as a consequence of ego depletion) is a plausible explanation for these effects.

To test this, Christiansen et al. (57) conducted a laboratory study to examine whether the effects of ego depletion on ad libitum alcohol consumption were mediated by increases in disinhibition, in a sample of heavy social drinkers. Their results demonstrated that ego depletion caused a marked increase in ad libitum alcohol consumption and also a slight increase in disinhibition, replicating the effects reported in the aforementioned studies (49, 50). However, increased ad libitum consumption after ego depletion was not mediated by changes in disinhibition. Instead, the effects on ad libitum consumption were mediated by the perceived effort of suppressing emotions and thoughts during the ego depletion manipulation. These findings are consistent with recent evidence demonstrating that ego depletion may not influence behavior because of an actual deficit of self-control resources, but instead because of the perceived effort and beliefs about ego depletion (i.e., the belief that self-control is a limited resource and one can be "at the end of one's tether"). For example, Job et al. (58) told participants that self-control was unlimited, and these instructions completely eliminated ego depletion effects. This was later replicated, but only in situations of minor ego depletion (59). Similarly, Alberts et al. (60) demonstrated that priming thoughts of persistence led to stable self-control, i.e., immunity from ego depletion effects. Finally, Clarkson et al. (61) showed that individuals who perceive themselves as less (versus more) depleted are somewhat protected against ego depletion effects. Considered together, these studies suggest that ego depletion effects are genuine phenomena, but they may be mediated by beliefs about self-control rather than a directly observable transient change in disinhibition [see also (48)]. The findings from the study by Christiansen et al. (57) demonstrate that this account may also explain the role played by ego depletion in substance use disorders.

\section{EXPOSURE TO DRUG-RELATED CUES ("CUE EXPOSURE"}

As noted in the previous section, disinhibition increases when substance users are exposed to substance-related cues. It is wellestablished that exposure to substance-related cues elicits a range of responses include physiological changes (such as increased heart rate and skin conductance), increased subjective craving, and increased drug self-administration (62). Some theorists have suggested that fluctuations in disinhibition may partially mediate the effects of drug cue exposure on craving, drug self-administration, and relapse in those attempting abstinence [e.g., (2)].

As we discussed in the previous section, there is compelling evidence that alcohol-related cues lead to increased disinhibition when presented to alcohol-dependent patients $[(49,50)$; see also (63)]. The pattern of results obtained from studies with nondependent drinkers is more mixed: both Weafer and Fillmore (64) and Petit et al. (65) demonstrated that alcohol-related pictures caused transient increases in disinhibited behavior. However Nederkoorn et al. (18) found no increase in disinhibition when social drinkers were exposed to alcohol-related pictures (versus other types of pictures), and Jones et al. (66) replicated the methodology of Gauggel et al. (50) in social drinkers and found no change in disinhibition after holding and sniffing an alcoholic drink (compared to exposure to a control drink). This suggests that alcoholdependent patients may be more vulnerable to fluctuations in disinhibition after exposure to alcohol cues than non-dependent individuals.

Is disinhibition implicated in cue reactivity? Papachristou et al. (67) demonstrated that individual differences in disinhibition (as assessed with a Stop Signal task) moderated cue-provoked craving: individuals exhibiting greater disinhibition showed a greater increase in craving following cue reactivity. In a subsequent study with alcohol-dependent patients, disinhibition predicted $13 \%$ of the variance (68) in peak craving following cue exposure. These studies demonstrate that individual differences in disinhibition can moderate the strength of subjective responses to alcohol cues, but they do not tell us if alcohol-related cues lead to increased disinhibition, and if cue-induced increases in disinhibition mediate other aspects of cue reactivity such as subjective craving and drug self-administration. To our knowledge, the only study to investigate this issue was recently performed by our group. We found that alcohol cues increased subjective alcohol craving and self-administration of alcohol, but had no effect on disinhibition; furthermore, disinhibition after cue exposure was correlated with the strength of craving, but was unrelated to alcohol selfadministration (66). Therefore, additional research is required to investigate whether state disinhibition might mediate the effects of alcohol cues on craving and drinking behavior.

\section{STRESS, AROUSAL, AND NEGATIVE EMOTIONAL STATES}

The handful of studies that investigated the effects of stress on disinhibition have yielded contradictory findings. For example, one study demonstrated that acute stress magnified the influence of alcohol-related cues on disinhibition (44), whereas Constantinou et al. (69) found that acute stress actually reduced disinhibition in opiate users and matched non-user controls. These findings may be reconciled if we carefully consider the severity of the stress response: Henderson et al. (70) demonstrated increased 
disinhibition after both high and low stress levels of stress, whereas moderate levels of stress led to reduced disinhibition. Therefore, we can speculate that the relationship between disinhibition and stress may follow a U-shaped function, although it is difficult to characterize and directly compare the severity of stress induced in the Constantinou et al. (69) and Zack et al. (44) studies.

Both negatively valenced and positively valenced stimuli can increase disinhibition. For example, increased disinhibition is seen in response to stimuli depicting painful situations (71), fear and biological threats (72). Positively valenced stimuli have similar disinhibiting effects $(73,74)$, that may be stronger than those produced by negative stimuli (75). In an interesting parallel to the literature on stress and disinhibition, it seems that the emotional intensity of the stimuli may be an important factor, because both positive facial expressions and (low intensity) threat images can reduce disinhibition, whilst high intensity threat increase it (76). Given that highly valenced images (both positive and negative) are also highly arousing (77), we can speculate that the relationship between arousal and disinhibition may also be U-shaped, much like the relationship between stress and disinhibition. High and low levels of arousal may interfere with the allocation of attention, creating conflict, and competition between inhibitory and attentional processes $(74,78)$. However, this is speculative and we highlight the need for further research to clarify the relationships between stress, arousal, and disinhibition.

The effects of arousal on disinhibition suggest an alternative explanation for the increased disinhibition that is seen following exposure to substance-related cues, given that it is well-established that substance-related cues lead to increased physiological arousal (62). Therefore, the mechanism through which substance-related cues lead to increased disinhibition may be as simple as increased arousal, a hypothesis which should be investigated in future research. We conclude this section by noting that substance-related cues, stressors, and highly arousing emotional events (which could be either positive or negative) are known to precipitate relapse to drug-seeking (79) and state fluctuations in disinhibition are a plausible mechanism to explain these effects. However, to our knowledge no research has assessed whether fluctuations in disinhibition caused by substance-related cues, stress, or arousal directly mediate drug-seeking.

\section{MOTIVATIONAL BIASES AND MENTAL SETS}

We have shown how environmental and psychological factors (ingestion of alcohol, ego depletion, substance-related cues, and stressors) can increase disinhibition. In this section we discuss "internal" factors, such as motivation and mental set, which are also known to alter disinhibition. Behavioral measures of disinhibition, in particular the Stop Signal task, set up a response conflict (a competition) between speed and accuracy (80). This response conflict can be experimentally manipulated, resulting in fluctuating disinhibition (81). For example, Leotti and Wager (82) propose that there are marked individual differences in the aversion to making mistakes, and these influence how a person would respond when completing a Stop Signal task. Imagine a person who is extremely averse to making mistakes: for this person, the conflict between responding rapidly and avoiding inhibition errors would be tipped in favor of avoiding inhibition errors, and this person would have a strategic bias that means they would make (relatively) few inhibition errors if they were to perform a Stop Signal task. It is possible to alter participants' strategic biases when they perform these tasks, for example by providing instructions and/or providing financial incentives that reward either rapid responding or successful inhibition. As an interesting aside, we note that similar incentives can overcome the effects of ego depletion (83) and psychomotor impairment after alcohol consumption (84), suggesting some degree of intentional control over the expression of disinhibited behavior (85).

Guerrieri et al. $(86)$ and Jones et al. $(87,88)$ were able to influence participants' responding during a Stop Signal task by manipulating task instructions. One group of participants were instructed to prioritize rapid responding rather than successful inhibition, whereas these instructions were reversed for a different group of participants. These instructions had the anticipated effects on performance on the Stop Signal task: the former group were faster to respond on "Go" trials but they made more inhibition errors, compared to the latter group, who were slow to respond on "Go" trials but were much more successful at inhibiting their responding. Arguably, this manipulation of task instructions changes participants' mental set while they complete the Stop Signal task. In the former group, a disinhibited mental set is temporarily induced, whereas a more restrained and cautious mental set is induced in the latter group. Once these disinhibited mental sets have been induced, this allows us to investigate whether disinhibited (versus restrained) mental sets have a causal influence on craving and food or alcohol consumption, something which was accomplished by measuring these things immediately after participants had completed the Stop Signal task. The findings were clear: participants in whom a disinhibited mental set had been induced subsequently consumed more food $(86)$ or beer $(87,88)$ compared to participants in whom a restrained mental set had been induced. A follow-up study demonstrated that these differential task instructions also influenced an electrophysiological index of (dis)inhibition, the amplitude of the P300b event-related potential (66). In all of the alcohol studies $(66,87,88)$, individual differences in disinhibition (both behavioral measures and their electrophysiological correlates) were positively correlated with consumption of beer: those participants who were most "disinhibited" after this manipulation of mental set, consumed the most beer immediately afterward. However, despite influencing drinking behavior, these task instructions had no effect on subjective alcohol craving in any of these studies. Overall, these studies provide direct support for the notion that a disinhibited mental set can lead to increased alcohol consumption, at least in laboratory settings. Importantly, this is not the same as directly "training" participants to act in a more or less disinhibited way, but this is an issue that we address in the following section.

\section{BOOSTING SELF-CONTROL: CAN WE TRAIN PEOPLE TO BE LESS DISINHIBITED?}

To summarize so far, we have demonstrated that disinhibition is an important feature of substance use disorders that may occur premorbidly to and serve as a risk-factor for the development of those disorders. Furthermore, various environmental and psychological variables are known to produce transient changes in disinhibition, 
and this fluctuating disinhibition may exert a causal influence on craving and substance consumption in the laboratory. From the clinical perspective, how can we exploit this knowledge in order to develop novel treatments for substance use disorders?

One novel approach to treatment would be to directly target the cognitive processes that have a causal influence on substance self-administration. This treatment strategy has the potential to complement (but not replace) existing approaches based on pharmacotherapy and "talking therapies" $(89,90)$. Despite this being a relatively underdeveloped area of research, some forms of this "cognitive training" appear to be effective in alcohol dependence $(91,92)$. This raises the question of whether inhibitory control can be directly trained. One approach is to require patients to repeatedly practice self-control tasks, something which should (in theory) increase the strength of the inhibitory control (or selfcontrol) "muscle," according to the resource model of self-control. Some studies have demonstrated that improving general control processes can lower alcohol consumption and reduce the risk of smoking relapse $(93,94)$. In more general terms, Hagger et al. (48) reported an overall large effect size for the effects of self-control training on health-related behaviors.

Working memory is important for maintaining task goals and updating information, which are considered important components that underlie self-control and effective inhibition $(95,96)$. Indeed, there is a large amount shared variance between the working memory and inhibitory control. Training working memory has been shown to reduce alcohol consumption at 1-month follow-up (97) and a combination of working memory and inhibition training improving health-related outcomes in obese children (98). Furthermore, training working memory have been shown to transfer to improvements in other cognitive tasks (99). It is therefore possible that the effects of working memory training on healthrelated outcomes may by partially attributable to improvements in inhibitory control. However, this issue has yet to be investigated.

In addition to training general control mechanisms, some recent studies have demonstrated that it may be possible (and beneficial) to train participants to improve their response inhibition specifically when they are faced with substance-related cues. In two studies, Houben and colleagues $(100,101)$ required their participants to perform a Go/No-Go task in which alcohol-related and neutral cues were embedded. One group of participants were always required to inhibit ("No-Go") when alcohol-related pictures were presented, and they always had to respond ("Go") when neutral cues were presented. In a different group, these contingencies were reversed. The primary finding was that, at 1-week follow-up, participants who had consistently inhibited their responses when presented with alcohol cues reported significantly reduced alcohol consumption, compared to the group who had consistently inhibited their responses when neutral cues were presented. However, there were no significant effects on alcohol self-administration in the laboratory when measured immediately after the end of training. These results were replicated in the second study (no immediate effects on alcohol consumption, but a clear reduction in self-reported alcohol consumption at follow-up after 1 week). In the second study, the authors also examined what mediated the effects of the training on alcohol consumption, and they found that the reduction in drinking was mediated by changes in automatic affective associations for alcohol cues rather than the (predicted) improvements in response inhibition. These findings support theories of inhibitory devaluation, which suggests that a conflict between wanting to respond to positive stimuli but having to inhibit is resolved by a devaluation of these stimuli $(102,103)$. This phenomenon has been applied to other hedonic stimuli such as food (104) and sexual images (105).

Jones and Field (106) used a similar training procedure, this time embedded in a Stop Signal task, in an attempt to extend the findings from the studies reported by Houben et al. $(100,101)$ and to try to identify an inhibition training procedure that may exert its beneficial effects by bolstering inhibitory control (rather than by changing affective associations with alcohol). Participants completed a Stop Signal task in which alcohol-related and neutral pictures were shown; participants were required to categorize the pictures as quickly as possible but to inhibit their responding whenever they heard a tone. In one group of participants, the majority of stop signal tones occurred during presentation of alcohol pictures, whereas for another group of participants the tone was paired with neutral pictures instead. Results indicated that the group that inhibited mainly to alcohol cues showed a progressive decrease in inhibition errors and slowing of reaction times to alcohol cues, over the course of multiple blocks of the task. Importantly, immediately after the training this group consumed less beer than participants in the control group, which suggests that this inhibition training - in which participants learn to inhibit their responding but only when alcohol-related pictures are presented on the computer screen - can have beneficial effects on drinking behavior. However, unlike in the studies reported by Houben et al. $(100,101)$, these beneficial effects of training were not evident at the 1-week follow-up. The immediate effects of cuespecific inhibition training on ad libitum alcohol consumption in the laboratory were replicated by Bowley et al. (107), who used a modified Go/No-Go task similar to that used by Houben et al. $(100,101)$. Those authors found that the reduction in alcohol consumption was comparable to that seen in an active control group that received a brief ( $5 \mathrm{~min}$ ) alcohol intervention. However, this study also failed to demonstrate beneficial effects of the training at 1-week follow-up.

At both Liverpool and Maastricht we are currently working on studies with more intensive training, conducted over multiple sessions and with longer follow-up periods, in an attempt to identify the optimum parameters for inhibition training to produce immediate reductions in alcohol consumption in the laboratory, together with reductions in drinking that can be maintained over the longer term. If further work suggests that this type of inhibition training is effective, it may work in a similar way to other types of cognitive training, by giving participants a few moments to resist their powerful tendencies to use the substance and to engage a more appropriate coping response instead [see (90)].

Beliefs about self-control: why we should be careful what we tell people about the role of disinhibition.

Whilst attempting to bolster inhibitory control may ultimately lead to a novel, effective method of treatment for substance use disorders, it is imperative that individuals are motivated to change their behavior. Many current treatments such as motivational interviewing and cognitive behavioral therapy aim to increase the 
motivation to change substance use behavior, and furnish patients with the skills needed to bring about and then maintain this behavior change $(108,109)$. As well as motivation to change behavior (i.e., exercise restraint), individuals' beliefs about their ability to inhibit their behavior may be important not only in terms of their substance use but also in terms of the applicability of these proposed interventions. Whilst it is generally acknowledged that having some confidence in the ability to control substance use is likely to increase the chances of maintaining abstinence, the evidence that this plays a major role is rather weak (110) and indeed, excessive self-efficacy ("over-confidence") may be detrimental to the chances of long-term success (111). Over-confident individuals may exhibit a "restraint bias," whereby unrealistic beliefs about the ability to control substance-seeking behavior may lead people to expose themselves to increased temptation, which results in substance use $(112,113)$. Therefore, beliefs about the ability to exercise restraint (or overcome disinhibition) may have a direct influence on substance-seeking behavior, but these beliefs might also moderate the influence of both alcohol intoxication and ego depletion on disinhibited behavior, as discussed in previous sections of this paper.

\section{CONCLUSIONS AND FUTURE DIRECTIONS}

The purpose of this review was to identify the environmental and psychological triggers that may cause disinhibition to fluctuate, and outline the implications of these fluctuations for the understanding and treatment of substance use disorders. The focus on state disinhibition is timely, because theoretical models now acknowledge that disinhibition is unlikely to function as a fixed and stable trait. Instead, temporary fluctuations in disinhibition may also contribute to substance use (2). The research reviewed in this paper lends support to this idea.

Given the emerging evidence discussed in this review, we propose a theoretical framework (visualized in Figure 1) that extends the hypothesis formulated by de Wit (2). We argue that individuals have a relatively stable capacity for inhibitory control, on the basis of research suggesting a general stability of inhibitory control throughout adulthood following maturation of the prefrontal cortex during adolescence $(114,115)$. This capacity is likely to be determined by a host of heritable and environmental factors which we have not addressed in detail here [but see $(7,116)]$, and like all human characteristics there is likely to be wide individual variation. It is also likely that this capacity may be reduced by neurotoxic effects of chronic substance use, particularly if this occurs during adolescence. Such neurotoxic effects have not yet been convincingly demonstrated but they are biologically plausible, and difficult to rule out on the basis of the research that is currently available [see (117)].

Within this relatively stable capacity for inhibitory control, we see "state" fluctuations in response to environmental triggers and motivational factors, as outlined in this review. Fluctuations in this state may increase the risk of substance use at particular times and in particular contexts, but the magnitude of these fluctuations (and their influence on behavior) is constrained by individual differences in the capacity for inhibitory control. Overlaid on top of this, the individual's beliefs about disinhibition and self-control can directly determine their behavior, including substance use. For example, individuals have beliefs about their ability to control behavior in the face of temptation [restraint beliefs c.f. $(112,113)$ ], about the effects of alcohol intoxication on disinhibition [intentionality c.f. (85)], and about the effects of self-control depletion on future behavior (59). We hypothesize that beliefs may interact with the capacity for inhibitory control, but they may also influence substance use independently as demonstrated by Jones et al. (112), and Nordgren et al. (113).

Priorities for future research include the identification of other factors that influence state fluctuations in disinhibition, and characterization of individual differences that may moderate these effects, e.g., personality constructs such as "ego-control" and "egoresiliency" $(118,119)$. Another important line of research is the development of new psychological interventions for substance use that can improve inhibitory control and mitigate the influence of environmental and motivational factors on state disinhibition. Whilst the recent studies have established proof-of-concept, it is unknown whether repeated inhibitory control training could promote long-lasting changes in drinking or other substance use. A recent review of the available literature suggests that inhibitory control may be "subject to fast plastic changes" (120). Therefore, it is possible that multiple sessions of inhibition training may increase an individual's capacity for inhibitory control, allowing for more behavioral flexibility when faced with the situational, psychological, and environmental factors discussed in this review. Therefore, inhibition training may provide a non-invasive adjunct to existing treatments [c.f. the effects of repeated working memory training (101) and approach bias training (92)].

Finally, future research should focus on improving the efficacy of this training and identifying the mechanism(s) of effect. Firstly, a comparison of different training mechanisms is needed as both the stop signal and Go/No-Go tasks are thought to measure subtly different forms of inhibition (action cancelation and action restraint, respectively). Therefore, modified versions of these task used for training are thought to improve automatic inhibition and controlled inhibition respectively [see explanations by (106, 120)]. It might be that training both forms of inhibition provides the most protection against state fluctuations. Secondly, the generalizability of inhibition training is currently unclear: data from Jones and Field (106) and Bowley et al. (107) suggest the effects of training did not generalize to drinking outside of the laboratory, whereas data from Houben et al. $(100,101)$ were more promising. Therefore, future research should attempt inhibition training in situations where individuals are likely to drink or in as many different contexts as possible, and it could be administered on a tablet computer or smartphone in naturalistic environments.

However, we emphasize that clinicians should employ caution when attempting to strengthen inhibitory control. Overconfidence in the ability to control behavior can be damaging and lead individuals to expose themselves to greater levels of temptation and increase their substance use. It is important to identify the optimum balance between the capacity for self-control, motivation to change behavior, and beliefs about the ability to exercise self-control. Finally, we note that the majority of research on this 


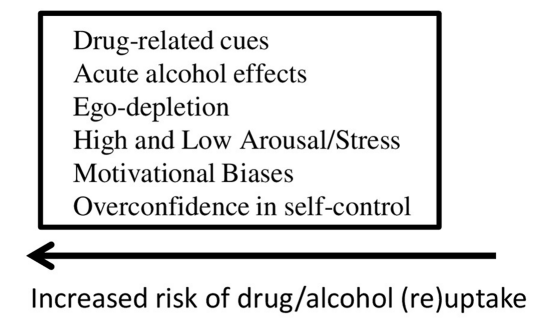

Stable capacity for inhibitory control (individual differences)

State (dis)inhibition,

fluctuates over time.
FIGURE 1 | Environmental triggers and psychological processes that underlie changes in state disinhibition, and their influence on substance use. Individuals have a stable capacity for inhibitory control, but a component of this capacity appears to fluctuate in response to environmental triggers and psychological processes. If individuals are in a disinhibited state, they are more likely to engage in substance use, or relapse to substance use after a period of abstinence. If individuals

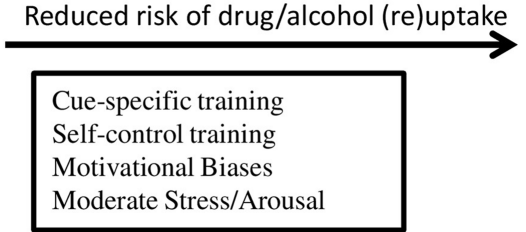

experience a decrease in state disinhibition, they are less likely to engage in substance use, or relapse. Drug-related cues, alcohol intoxication, ego depletion, arousal, stress, motivational biases, and over-confidence all lead to increased disinhibition and thereby increase the risk of substance use. Disinhibition can be reduced after different types of cognitive training, by motivational biases, and by moderate levels of stress and arousal - resulting in a reduced risk of substance use. topic that has been conducted to date has investigated alcohol use disorders, and there is a pressing need to investigate whether these principles apply to other substance use disorders as well.

To conclude, in this review we have identified the environmental triggers and psychological processes that can cause disinhibition to fluctuate, and shown that these fluctuations can increase substance use. Further research is needed to clarify the psychological mechanisms that underlie these effects, and to exploit this knowledge in order to develop new psychological treatments for substance use disorders.

\section{ACKNOWLEDGMENTS}

Funded by a research grant from the Medical Research Council, reference MR/K001558.
7. Verdejo-Garcia A, Lawrence AJ, Clark L. Impulsivity as a vulnerability marker for substance-use disorders: review of findings from high-risk research, problem gamblers and genetic association studies. Neurosci Biobehav Rev (2008) 32(4):777-810. doi:10.1016/j. neubiorev.2007.11.003

8. Goudriaan AE, Oosterlaan J, De Beurs E, Van Den Brink W. Neurocognitive functions in pathological gambling: a comparison with alcohol dependence, Tourette syndrome and normal controls. Addiction (2006) 101(4):534-47. doi:10.1111/j.1360-0443.2006. 01380.x

9. Lawrence AJ, Luty J, Bogdan NA, Sahakian BJ, Clark L. Impulsivity and response inhibition in alcohol dependence and problem gambling. Psychopharmacology (2009) 207(1):163-72. doi:10. 1007/s00213-009-1645-x

10. Zago-Gomes M, NakamuraPalacios EM. Cognitive components of frontal lobe function in alcoholics classified according to Lesch's typology. Alcohol Alcohol (2009) 44(5):449-57. doi:10.1093/alcalc/agp043 of alcoholism and their role in therapy. Alcohol Alcohol (1996) 31(Suppl 1):63-7. doi:10.1093/ oxfordjournals.alcalc.a008221

12. Fillmore MT, Rush CR. Impaired inhibitory control of behavior in hol Depend (2002) 66(3):265-73. doi:10.1016/S0376-8716(01) 00206-X
11. Lesch OM, Walter H. Subtypes chronic cocaine users. Drug Alco- responses: a model and a method.

J Exp Psychol Hum Percept Perform 113(2-3):139-46. do 1016/j.drugalcdep.2010.07.027 
13. Monterosso JR, Aron AR, Cordova X, Xu J, London ED. Deficits in response inhibition associated with chronic methamphetamine abuse. Drug Alcohol Depend (2005) 79(2):273-7. doi:10.1016/j. drugalcdep.2005.02.002

14. Billieux J, Gay P, Rochat L, Khazaal Y, Zullino D, Van der Linden M. Lack of inhibitory control predicts cigarette smoking dependence: evidence from a non-deprived sample of light to moderate smokers. Drug Alcohol Depend (2010) 112(1-2): 164-7. doi:10.1016/j.drugalcdep. 2010.06.006

15. Colder CR, O'Connor R. Attention biases and disinhibited behavior as predictors of alcohol use and enhancement reasons for drinking. Psychol Addict Behav (2002) 16(4):325-32. doi:10.1037/0893164X.16.4.325

16. Christiansen P, Cole JC, Goudie AJ, Field M. Components of behavioural impulsivity and automatic cue approach predict unique variance in hazardous drinking. Psychopharmacology (2012) 219(2):501-10. doi:10.1007/s00213-011-2396-z

17. Murphy P, Garavan H. Cognitive predictors of problem drinking and AUDIT scores among college students. Drug Alcohol Depend (2011) 115(1-2):94-100. doi:10. 1016/j.drugalcdep.2010.10.011

18. Nederkoorn C, Baltus M, Guerrieri R, Wiers RW. Heavy drinking is associated with deficient response inhibition in women but not in men. Pharmacol Biochem Behav (2009) 93(3):331-6. doi:10.1016/j. pbb.2009.04.015

19. Fernie G, Cole JC, Goudie AJ, Field M. Risk-taking but not response inhibition or delay discounting predict alcohol consumption in social drinkers. Drug Alcohol Depend (2010) 112:54-61. doi:10. 1016/j.drugalcdep.2010.05.011

20. Yan P, Li CS. Decreased amygdala activation during risk taking in non-dependent habitual alcohol users: a preliminary fMRI study of the stop signal task. Am J Drug Alcohol Abuse (2009) 35(5):284-9. doi:10.1080/ 00952990902968569

21. Dick DM, Smith G, Olausson P, Mitchell SH, Leeman RF, O'Malley SS, et al. Understanding the construct of impulsivity and its relationship to alcohol use disorders. Addict Biol (2010) 15(2):217-26. doi:10.1111/j.13691600.2009.00190.x
22. Crews FT, Boettiger CA. Impulsivity, frontal lobes and risk for addiction. Pharmacol Biochem Behav (2009) 93(3):237-47. doi:10.1016/ j.pbb.2009.04.018

23. Crews FT, Collins MA, Dlugos C, Littleton J, Wilkins L, Neafsey EJ, et al. Alcohol-induced neurodegeneration: when, where and why? Alcohol Clin Exp Res (2004) 28(2):350-64. doi:10.1097/ 01.ALC.0000113416.65546.01

24. Chanraud S, Martelli C, Delain F, Kostogianni N, Douaud G, Aubin $\mathrm{HJ}$, et al. Brain morphometry and cognitive performance in detoxified alcohol-dependents with preserved psychosocial functioning. Neuropsychopharmacology (2007) 32(2):429-38. doi:10.1038/sj.npp. 1301219

25. Goldstein RZ, Volkow ND. Drug addiction and its underlying neurobiological basis: neuroimaging evidence for the involvement of the frontal cortex. Am J Psychiatry (2002) 159(10):1642-52. doi: 10.1176/appi.ajp.159.10.1642

26. Koob GF, Volkow ND. Neurocircuitry of addiction. Neuropsychopharmacology (2010) 35(1):217-38. doi:10.1038/npp.2009.110

27. Bonthius DJ, West JR. Alcoholinduced neuronal loss in developing rats: increased brain damage with binge exposure. Alcohol Clin Exp Res (1990) 14(1):107-18. doi:10.1111/j.1530-0277.1990. tb00455.x

28. Crews FT, Braun CJ, Hoplight B, Switzer Iii RC, Knapp DJ. Binge ethanol consumption causes differential brain damage in young adolescent rats compared with adult rats. Alcohol Clin Exp Res (2000) 24(11):1712-23. doi:10. 1111/j.1530-0277.2000.tb01973.x

29. Nixon K, Crews FT. Binge ethanol exposure decreases neurogenesis in adult rat hippocampus. $J$ Neurochem (2002) 83(5):1087-93. doi:10.1046/j.1471-4159.2002. 01214.x

30. Nigg JT, Wong MM, Martel MM, Jester JM, Puttler LI, Glass JM, et al. Poor response inhibition as a predictor of problem drinking and illicit drug use in adolescents at risk for alcoholism and other substance use disorders. J Am Acad Child Adolesc Psychiatry (2006) 45(4):468-75. doi:10.1097/01.chi. 0000199028.76452.a9

31. Tarter RE, Kirisci L, Habeych M, Reynolds $M$, Vanyukov $M$. Neurobehavior disinhibition in childhood predisposes boys to substance use disorder by young adulthood: direct and mediated etiologic pathways. Drug Alcoho Depend (2004) 73(2):121-32. doi:10.1016/j.drugalcdep.2003.07. 004

32. Tarter RE, Kirisci L, Reynolds M, Mezzich A. Neurobehavior disinhibition in childhood predicts suicide potential and substance use disorder by young adulthood. Drug Alcohol Depend (2004) 76(Suppl). doi:10.1016/j. drugalcdep.2004.08.006

33. Wong MM, Zucker RA, Puttler LI, Nigg JT, Fitzgerald HE, Jester $\mathrm{JM}$, et al. Behavioral control and resiliency in the onset of alcohol and illicit drug use: a prospective study from preschool to adolescence. Child Dev (2006) 77(4):1016-33. doi:10.1111/j. 1467-8624.2006.00916.x

34. Fernie G, Peeters P, Gullo MJ, Christiansen P, Cole J, Sumnall $\mathrm{H}$, et al. Multiple components of impulsivity predict prospective alcohol involvement in adolescents. Addiction (2013) 108(11):1916-23. doi:10.1111/add.12283

35. Rubio G, Jiménez M, RodríguezJiménez R, Martínez I, Avila C, Ferre F, et al. The role of behavioral impulsivity in the development of alcohol dependence: a 4-year follow-up study. Alcohol Clin Exp Res (2008) 32(9):1681-7. doi:10. 1111/j.1530-0277.2008.00746.x

36. Lee SS, Humphreys KL, Flory K, Liu R, Glass K. Prospective association of childhood attention-deficit/hyperactivity disorder (ADHD) and substance use and abuse/dependence: a metaanalytic review. Clin Psychol Rev (2011) 31(3):328-41. doi:10.1016/ j.cpr.2011.01.006

37. de Wit H. Priming effects with drugs and other reinforcers. Exp Clin Psychopharmacol (1996) 4(1):5-10. doi:10.1037/1064-1297.4.1.5

38. Rose AK, Duka T. Effects of dose and time on the ability of alcohol to prime social drinkers. Behav Pharmacol (2006) 17(1):61-70. doi:10. 1097/01.fbp.0000189814.61802.92

39. Caswell A, Morgan M, Duka T. Acute alcohol effects on subtypes of impulsivity and the role of alcohol-outcome expectancies. Psychopharmacology (2013) 229(1):21-30. doi:10.1007/s00213-013-3079-8

40. Weafer J, Fillmore MT. Comparison of alcohol impairment of behavioral and attentional inhibition. Drug Alcohol Depend (2012) 126(1-2):176-82. doi:10. 1016/j.drugalcdep.2012.05.010

41. Fillmore MT. Acute alcoholinduced impairment of cognitive functions: past and present findings. Int J Disabil Hum Dev (2007) 6(2):115-25.

42. Field M, Wiers RW, Christiansen P, Fillmore MT, Verster JC. Acute alcohol effects on inhibitory control and implicit cognition: implications for loss of control over drinking. Alcohol Clin Exp Res (2010) 34(8):1346-52. doi:10. 1111/j.1530-0277.2010.01218.x

43. Adams S, Ataya AF, Attwood AS, Munafò MR. Effects of alcohol on disinhibition towards alcoholrelated cues. Drug Alcohol Depend (2013) 127(1-3):137-42. doi:10. 1016/j.drugalcdep.2012.06.025

44. Zack M, Woodford TM, Tremblay AM, Steinberg L, Zawertailo LA, Busto UE. Stress and alcohol cues exert conjoint effects on go and stop signal responding in male problem drinkers. Neuropsychopharmacology (2011) 36(2):445-58. doi:10. 1038/npp.2010.177

45. Weafer J, Fillmore MT. Individual differences in acute alcohol impairment of inhibitory control predict ad libitum alcohol consumption. Psychopharmacology (2008) 201(3):315-24. doi: 10.1007/s00213-008-1284-7

46. Christiansen P, Rose AK, Cole JC, Field M. A comparison of the anticipated and pharmacological effects of alcohol on cognitive bias, executive function, craving and adlib drinking. J Psychopharmacol (2013) 27(1):84-92. doi:10.1177/ 0269881112450787

47. Baumeister RF, Muraven M, Tice DM. Ego depletion: a resource model of volition, self-regulation, and controlled processing. Soc Cogn (2000) 18(2):130-50. doi:10. 1521/soco.2000.18.2.130

48. Hagger MS, Wood C, Stiff C, Chatzisarantis NLD. Ego depletion and the strength model of selfcontrol: a meta-analysis. Psychol Bull (2010) 136(4):495-525. doi: $10.1037 / \mathrm{a} 0019486$

49. Muraven M, Shmueli D. The selfcontrol costs of fighting the temptation to drink. Psychol Addict Behav (2006) 20(2):154-60. doi: 10.1037/0893-164X.20.2.154

50. Gauggel S, Heusinger A, Forkmann T, Boecker M, Lindenmeyer J, Miles Cox W, et al. Effects of alcohol cue exposure on response inhibition in detoxified alcohol-dependent 
patients. Alcohol Clin Exp Res (2010) 34(9):1584-9. doi:10.1111/ j.1530-0277.2010.01243.x

51. Mainz V, Drüke B, Boecker M, Kessel R, Gauggel S, Forkmann T. Influence of cue exposure on inhibitory control and brain activation in patients with alcohol dependence. Front Hum Neurosci (2012) 6:92. doi:10.3389/fnhum. 2012.00092

52. Muraven M, Collins RL, Nienhaus K. Self-control and alcohol restraint: an initial application of the self-control strength model. Psychol Addict Behav (2002) 16(2):113-20. doi:10.1037/0893-164X.16.2.113

53. Friese $M$, Hofmann W, Wänke M. When impulses take over: moderated predictive validity of explicit and implicit attitude measures in predicting food choice and consumption behaviour. Br J Soc Psychol (2008) 47(3):397-419. doi:10.1348/ 014466607X241540

54. Muraven M, Collins RL, Shiffman S, Paty JA. Daily fluctuations in self-control demands and alcohol intake. Psychol Addict Behav (2005) 19(2):140-7. doi:10.1037/ 0893-164X.19.2.140

55. Collins RL, Lapp WM. Restraint and attributions: evidence of the abstinence violation effect in alcohol consumption. Cognit Ther Res (1991) 15(1):69-84. doi:10.1007/ BF01172943

56. Collins RL, Lapp WM, Izzo CV. Affective and behavioral reactions to the violation of limits on alcohol consumption. J Stud Alcohol (1994) 55(4):475-86.

57. Christiansen P, Cole JC, Field M. Ego depletion increases ad-lib alcohol consumption: investigating cognitive mediators and moderators. Exp Clin Psychopharmacol (2012) 20(2):118-28. doi:10.1037/ a0026623

58. Job V, Dweck CS, Walton GM. Ego depletion-is it all in your head? Implicit theories about willpower affect self-regulation. Psychol Sci (2010) 21(11):1686-93. doi:10. 1177/0956797610384745

59. Vohs KD, Baumeister RF, Schmeichel BJ. Motivation, personal beliefs, and limited resources all contribute to self-control. JExp Soc Psychol (2012) 48(4):943-7. doi: 10.1016/j.jesp.2012.03.002

60. Alberts HJEM, Martijn C, Greb J, Merckelbach H, De Vries NK. Carrying on or giving in: the role of automatic processes in overcoming ego depletion. Br J Soc Psychol
(2007) 46(2):383-99. doi:10.1348/ 014466606X130111

61. Clarkson JJ, Hirt ER, Jia L, Alexander MB. When perception is more than reality: the effects of perceived versus actual resource depletion on self-regulatory behavior. J Pers Soc Psychol (2010) 98(1):29-46. doi: 10.1037/a0017539

62. Carter BL, Tiffany ST. Metaanalysis of cue-reactivity in addiction research. Addiction (1999) 94(3):327-40. doi:10.1046/j.13600443.1999.9433273.x

63. Noel $X$, Van Der Linden $M$, D'Acremont $M$, Bechara A, Dan B, Hanak C, et al. Alcohol cues increase cognitive impulsivity in individuals with alcoholism. Psychopharmacology (2007) 192(2):291-8. doi:10.1007/s00213-006-0695-6

64. Weafer J, Fillmore MT. Alcohol-related stimuli reduce inhibitory control of behavior in drinkers. Psychopharmacology (2012) 3:489-98. doi:10.1007/s00213-012-2667-3

65. Petit G, Kornreich C, Noël $\mathrm{X}$, Verbanck P, Campanella S. Alcohol-related context modulates performance of social drinkers in a visual go/no-go task: a preliminary assessment of event-related potentials. PLoS One (2012) 7:e37466. doi:10.1371/journal. pone. 0037466

66. Jones A, Field M, Christiansen P, Stancak A. P300 during response inhibition is associated with ad-lib alcohol consumption in social drinkers. J Psychopharmacol (2013) 27(6):507-14. doi:10.1177/0269881113485142

67. Papachristou H, Nederkoorn C, Havermans R, Van Der Horst M, Jansen A. Can't stop the craving: the effect of impulsivity on cue-elicited craving for alcohol in heavy and light social drinkers. Psychopharmacology (2012) 219(2):511-8. doi:10. 1007/s00213-011-2240-5

68. Papachristou H, Nederkoorn C, Havermans R, Bongers P, Beunen $S$, Jansen A. Higher levels of trait impulsiveness and a less effective response inhibition are linked to more intense cue-elicited craving for alcohol in alcoholdependent patients. Psychopharmacology (2013) 228:641-9. doi: 10.1007/s00213-013-3063-3

69. Constantinou N, Morgan CJA, Battistella S, O'Ryan D, Davis P, Curran HV. Attentional bias, inhibitory control and acute stress in current and former opiate addicts. Drug Alcohol Depend (2010) 109(1-3):220-5. doi:10. 1016/j.drugalcdep.2010.01.012

70. Henderson RL, Snyder HR, Gupta T, Banich MT. When does stress help or harm? The effects of stress controllability and subjective stress response on stroop performance. Front Psychol (2012) 3:179. doi:10. 3389/fpsyg.2012.00179

71. Yu J, Hung DL, Tseng P, Tzeng OJL, Muggleton NG, Juan CH. Sex differences in how erotic and painful stimuli impair inhibitory control. Cognition (2012) 124(2):251-5. doi:10.1016/j.cognition.2012.04. 007

72. Hartikainen KM, Siiskonen AR, Ogawa KH. Threat interferes with response inhibition. Neuroreport (2012) 23(7):447-50. doi:10.1097/ WNR.0b013e3283531e74

73. Kalanthroff E, Cohen N, Henik A. Stop feeling: inhibition of emotional interference following stopsignal trials. Front Hum Neurosci (2013) 7:78. doi:10.3389/fnhum. 2013.00078

74. Verbruggen F, De Houwer J. Do emotional stimuli interfere with response inhibition? Evidence from the stop signal paradigm. Cogn Emot (2007) 21(2):391-403. doi:10.1080/02699930600625081

75. Albert J, López-Martín S, Tapia M, Montoya D, Carretié L. The role of the anterior cingulate cortex in emotional response inhibition. Hum Brain Mapp (2012) 33(9):2147-60. doi:10.1002/hbm. 21347

76. Pessoa L, Padmala S, Kenzer A, Bauer A. Interactions between cognition and emotion during response inhibition. Emotion (2012) 12(1):192-7. doi:10.1037/a0024109

77. Lang PJ, Bradley MM, Cuthbert BN. Emotion, motivation, and anxiety: brain mechanisms and psychophysiology. Biol Psychiatry (1998) 44(12):1248-63.

78. Pessoa L. How do emotion and motivation direct executive control? Trends $\operatorname{Cog} n \mathrm{Sci}$ (2009) 13(4):160-6. doi:10.1016/j. tics.2009.01.006

79. Hodgins DC, El-Guebaly N, Armstrong S. Prospective and retrospective reports of mood states before relapse to substance use. $J$ Consult Clin Psychol (1995) 63(3):400-7. doi:10.1037/0022-006X.63.3.400

80. Band GPH, van der Molen MW, Logan GD. Horse-race model simulations of the stop-signal procedure. Acta Psychol (2003)
112(2):105-42. doi:10.1016/ S0001-6918(02)00079-3

81. Ramautar JR, Kok A, Ridderinkhof KR. Effects of stop-signal probability in the stop-signal paradigm: the N2/P3 complex further validated. Brain Cogn (2004) 56(2): 234-52. doi:10.1016/j.bandc.2004 07.002

82. Leotti LA, Wager TD. Motivational influences on response inhibition measures. J Exp Psychol Hum Percept Perform (2010) 36(2):430-47. doi: $10.1037 / \mathrm{a} 0016802$

83. Baumeister RF, Nathan Dewall C, Ciarocco NJ, Twenge JM. Social exclusion impairs selfregulation. $J$ Pers Soc Psychol (2005) 88(4):589-604. doi:10.1037/0022-3514.88.4.589

84. Fillmore MT, Vogel-Sprott M. Response inhibition under alcohol: effects of cognitive and motivational conflict. J Stud Alcohol (2000) 61(2):239-46.

85. Vogel-Sprott M, Easdon C, Fillmore M, Finn P, Justus A. Alcohol and behavioral control: cognitive and neural mechanisms. Alcohol Clin Exp Res (2001) 25(1):117-21. doi:10.1111/j.15300277.2001.tb02135.x

86. Guerrieri R, Nederkoorn C, Schrooten M, Martijn C, Jansen A. Inducing impulsivity leads high and low restrained eaters into overeating, whereas current dieters stick to their diet. Appetite (2009) 53(1):93-100. doi:10.1016/j.appet. 2009.05.013

87. Jones A, Cole J, Goudie A, Field M. Priming a restrained mental set reduces alcohol-seeking independently of mood. Psychopharmacology (2011) 218:557-65. doi: 10.1007/s00213-011-2338-9

88. Jones A, Guerrieri R, Fernie G, Cole J, Goudie A, Field M. The effects of priming restrained versus disinhibited behaviour on alcohol-seeking in social drinkers. Drug Alcohol Depend (2011) 113(1):55-61. doi:10.1016/ j.drugalcdep.2010.07.006

89. Friese M, Hofmann W, Wiers RW. On taming horses and strengthening riders: recent developments in research on interventions to improve self-control in health behaviors. Self Identity (2011) 10(3):336-51. doi:10.1080/ 15298868.2010 .536417

90. Wiers RW, Gladwin TE, Hofmann W, Salemink E, Ridderinkhof KR. Cognitive bias modification and cognitive control training in addiction and related psychopathology: mechanisms, 
clinical perspectives, and ways forward. Clin Psychol Sci (2013) 1(2):192-212. doi:10.1177/2167702612466547

91. Eberl C, Wiers RW, Pawelczack S, Rinck M, Becker ES, Lindenmeyer J. Approach bias modification in alcohol dependence: do clinical effects replicate and for whom does it work best? Dev Cogn Neurosci (2013) 4:38-51. doi:10.1016/j.dcn. 2012.11.002

92. Wiers RW, Eberl C, Rinck M, Becker ES, Lindenmeyer J. Retraining automatic action tendencies changes alcoholic patients' approach bias for alcohol and improves treatment outcome. Psychol Sci (2011) 22(4):490-7. doi: 10.1177/0956797611400615

93. Muraven M. Practicing selfcontrol lowers the risk of smoking lapse. Psychol Addict Behav (2010) 24(3):446-52. doi:10.1037/a0018545

94. Oaten M, Cheng K. Longitudinal gains in self-regulation from regular physical exercise. $\mathrm{Br} J$ Health Psychol (2006) 11(4):717-33. doi: 10.1348/135910706X96481

95. Miyake A, Friedman NP. The nature and organization of individual differences in executive functions: four general conclusions. Curr Dir Psychol Sci (2012) 21(1):8-14. doi:10.1177/0963721411429458

96. Munakata Y, Herd SA, Chatham $\mathrm{CH}$, Depue BE, Banich MT, O'Reilly RC. A unified framework for inhibitory control. Trends $\operatorname{Cog} n$ Sci (2011) 15(10):453-9. doi:10. 1016/j.tics.2011.07.011

97. Houben K, Wiers RW, Jansen A. Getting a grip on drinking behavior. Psychol Sci (2011) 22:968-75. doi:10.1177/0956797611412392

98. Verbeken S, Braet C, Goossens L, van der Oord S. Executive function training with game elements for obese children: a novel treatment to enhance self-regulatory abilities for weight-control. Behav Res Ther (2013) 51(6):290-9. doi:10.1016/j. brat.2013.02.006

99. Klingberg T. Training and plasticity of working memory. Trends Cogn Sci (2010) 14(7):317-24. doi: 10.1016/j.tics.2010.05.002
100. Houben K, Havermans RC, Nederkoorn $\mathrm{C}$, Jansen $\mathrm{A}$. Beer à no-go: learning to stop responding to alcohol cues reduces alcohol intake via reduced affective associations rather than increased response inhibition. Addiction (2012) 107(7):1280-7. doi:10.1111/j. 1360-0443.2012.03827x

101. Houben K, Nederkoorn C, Wiers RW, Jansen A. Resisting temptation: decreasing alcohol-related affect and drinking behavior by training response inhibition. Drug Alcohol Depend (2011) 116(1-3):132-6. doi:10.1016/j. drugalcdep.2010.12.011

102. Veling H, Holland RW, van Knippenberg A. When approach motivation and behavioral inhibition collide: behavior regulation through stimulus devaluation. J Exp Soc Psychol (2008) 44(4):1013-9. doi:10.1016/j.jesp. 2008.03.004

103. Frischen A, Ferrey AE, Burt DH, Pistchik M, Fenske MJ. The affective consequences of cognitive inhibition: devaluation or neutralization? $J$ Exp Psychol Hum Percept Perform (2012) 38(1):169-79. doi:10.1037/a0025981

104. Veling H, Aarts H, Stroebe W. Using stop signals to reduce impulsive choices for palatable unhealthy foods. Br J Health Psychol (2013) 18(2):354-68. doi:10.1111/j.20448287.2012.02092.x

105. Ferrey AE, Frischen A, Fenske MJ. Hot or not: response inhibition reduces the hedonic value and motivational incentive of sexual stimuli. Front Psychol (2012) 3:575. doi:10.3389/fpsyg.2012. 00575

106. Jones A, Field M. The effects of cue-specific inhibition training on alcohol consumption in heavy social drinkers. J Exp Clin Psychopharmacol (2013) 21:8-16. doi: 10.1037/a0030683

107. Bowley C, Faricy C, Hegarty B, Johnstone SJ, Smith J, Kelly P, et al. The effects of inhibitory control training on alcohol consumption, implicit alcohol-related cognitions and brain electrical activity. Int J Psychophysiol (2013)
89(3):342-8. doi:10.1016/j. ijpsycho.2013.04.011

108. Larimer ME, Palmer RS, Marlatt GA. Relapse prevention: an overview of Marlatt's cognitivebehavioral model. Alcoh Res Health (1999) 23(2):151-60.

109. Miller WR. Motivational interviewing: research, practice, and puzzles. Addict Behav (1996) 21(6):835-42. doi:10.1016/03064603(96)00044-5

110. Gwaltney CJ, Metrik J, Kahler CW, Shiffman S. Self-efficacy and smoking cessation: a metaanalysis. Psychol Addict Behav (2009) 23(1):56-66. doi:10.1037/ a0013529

111. Staring AB, Breteler $\mathrm{MH}$. Decline in smoking cessation rate associated with high self-efficacy scores. Prev Med (2004) 39(5):863-8. doi:10.1016/j.ypmed.2004.03.025

112. Jones A, Cole J, Goudie A, Field M. The effect of restraint beliefs on alcohol-seeking behavior. Psychol Addict Behav (2012) 26(2):325-9. doi:10.1037/a0025546

113. Nordgren LF, Van Harreveld F, Van Der Pligt J. The restraint bias: how the illusion of self-restraint promotes impulsive behavior. Psychol Sci (2009) 20(12):1523-8. doi:10.1111/j.1467-9280.2009. 02468.x

114. Bedard AC, Nichols S, Barbosa JA, Schachar R, Logan GD, Tannock R. The development of selective inhibitory control across the life span. Dev Neuropsychol (2002) 21(1):93-111. doi:10.1207/ S15326942DN2101_5

115. Williams BR, Ponesse JS, Schachar RJ, Logan GD, Tannock R. Development of inhibitory control across the life span. Dev Psychol (1999) 35(1):205-13. doi:10.1037/ 0012-1649.35.1.205

116. Ersche KD, Jones PS, Williams GB, Turton AJ, Robbins, TW, Bullmore ET. Abnormal brain structure implicated in stimulant drug addiction. Science (2012) 335(6068):601-4. doi:10. 1126/science. 1214463

117. Peeters M, Vollebergh W, Wiers RW, Field M. Psychological changes and cognitive impairments in adolescent heavy drinkers. Alcohol Alcohol (2013) (in press).

118. Funder DC, Block JH, Block J. Delay of gratification: some longitudinal personality correlates. J Pers Soc Psychol (1983) 44(6):1198-213. doi:10.1037/0022-3514.44.6.1198

119. Letzring TD, Block J, Funder DC. Ego-control and ego-resiliency: generalization of self-report scales based on personality descriptions from acquaintances, clinicians, and the self. J Res Pers (2005) 39(4):395-422. doi:10.1016/j.jrp. 2004.06.003

120. Spierer L, Chavan CF, Manuel AL. Training-induced behavioral and brain plasticity in inhibitory control. Front Hum Neurosci (2013) 7:427. doi:10.3389/fnhum.2013.00427

Conflict of Interest Statement: The authors declare that the research was conducted in the absence of any commercial or financial relationships that could be construed as a potential conflict of interest.

Received: 24 January 2013; accepted: 07 October 2013; published online: 22 October 2013.

Citation: Jones A, Christiansen P, Nederkoorn $C$, Houben $K$ and Field $M$ (2013) Fluctuating disinhibition: implications for the understanding and treatment of alcohol and other substance use disorders. Front. Psychiatry 4:140. doi: 10.3389/fpsyt.2013.00140

This article was submitted to Addictive Disorders and Behavioral Dyscontrol, a section of the journal Frontiers in Psychiatry.

Copyright () 2013 Jones, Christiansen, Nederkoorn, Houben and Field. This is an open-access article distributed under the terms of the Creative Commons Attribution License (CC BY). The use, distribution or reproduction in other forums is permitted, provided the original author(s) or licensor are credited and that the original publication in this journal is cited, in accordance with accepted academic practice. No use, distribution or reproduction is permitted which does not comply with these terms. 